\title{
BMJ Open Dilemmas in delivering health promotion activities: findings from a qualitative study of mental health nurses in Denmark
}

\author{
Jane Ege Møller (D) , ${ }^{1}$ Anne Møller, ${ }^{2}$ Loni Ledderer ${ }^{2}$
}

To cite: Møller JE, Møller A, Ledderer L. Dilemmas in delivering health promotion activities: findings from a qualitative study of mental health nurses in Denmark. BMJ Open 2020;10:e036403. doi:10.1136/ bmjopen-2019-036403

- Prepublication history and additional material for this paper is available online. To view these files, please visit the journal online (http://dx.doi.org/10. 1136/bmjopen-2019-036403)

Received 17 December 2019 Revised 25 November 2020 Accepted 02 December 2020

Check for updates

(C) Author(s) (or their employer(s)) 2020. Re-use permitted under CC BY-NC. No commercial re-use. See rights and permissions. Published by BMJ.

${ }^{1}$ Department of Clinical Medicine, Aarhus University, Aarhus, Denmark

${ }^{2}$ Department of Public Health, Section of Health Promotion and Health Services, Aarhus University, Aarhus, Denmark

Correspondence to Dr Jane Ege Møller; Jane@clin.au.dk

\section{ABSTRACT}

Objective Recent studies have shown that people with mental illnesses have higher mortality and morbidity rates due to long-term conditions and lifestyle diseases. This knowledge has led to health promotion initiatives in mental health care to improve the physical health of people with mental illness. This article explores how mental health nurses experience working with health promotion activities in mental healthcare practices.

Design We adopted a qualitative research design using an interactive approach. Qualitative content analysis was used to develop the analytical framework.

Participants Focus groups $(n=7 ; n=5)$ were conducted with two groups of mental health nurses who attended health specialist training sessions in Denmark in the spring and fall of 2018.

Results The findings showed that working with health promotion activities in mental health care created two dilemmas for the mental health nurses: (1) dilemmas related to health promotion that involved discrepancies between the health promotion activities that were offered and patients' autonomy and wishes, and (2) systemrelated dilemmas stemming from working with screening for risk factors and documentation programmes. The mental health nurses developed different strategies to navigate these dilemmas, such as devising interview techniques for the screening questions and bending guidelines.

Conclusions Mental health nurses found it challenging to implement health promotion activities in mental health care, although they generally found these activities meaningful. The findings show that new health promotion activities need to be adapted to nurses' existing mental healthcare practices; however, this may require some adaptation of existing nursing practices.

\section{INTRODUCTION}

Currently, there is increased focus on health promotion in mental health. ${ }^{1}$ The reason for this is the disturbing fact that people suffering from serious mental illness face a high risk of lifestyle-related health problems, and higher mortality and morbidity rates than the rest of the population. ${ }^{2-6}$ Numerous studies have identified that the prevalence of risk factors and long-term diseases is much

\section{Strengths and limitations of this study}

- Focus groups enabled unique insights into mental health nurses' experiences of health promotion initiatives in mental healthcare practices.

- The focus groups were based on mental health nurses' case descriptions of everyday clinical practices, which allowed for questions directly relating to their work experiences.

- A limitation of this study is the low number of focus groups which prevented us from achieving full data saturation.

- Although one researcher was involved in teaching health promotion to the mental health nurses, transparent discussion and iterative data analysis reassured us that multiple interpretations had been considered.

higher among people with mental illness than the general population. ${ }^{578}$ The general life expectancy of people with mental illness has been estimated to be up to 25 years shorter than the general population, ${ }^{9}$ and while $40 \%$ of this higher mortality can be attributed to external causes (primarily suicide and accidents), approximately $60 \%$ relates to physical health. ${ }^{40}$

These major challenges in the mental health area call for action among healthcare providers. The solution to the problem has been to integrate health promotion initiatives into mental health care to a higher degree, ${ }^{11}$ and it has been suggested that mental health nurses should play an active role in such initiatives. ${ }^{12}$ According to the Ottawa Charter, health promotion is a "resource for everyday life, not the objective of living". ${ }^{13}$ Health promotion concerns physical, mental and social well-being in a broad sense. ${ }^{13-15}$ This definition provides a value basis for health promotion $^{16}$ and addresses individuals' quality of life and also demands for mental health in health services and health policies. ${ }^{15}$ 
However, implementing health promotion initiatives in healthcare practice has not been a simple task. Studies have explored how implementing health promotion in mental health care involves numerous challenges such as resource shortages, organisational culture and inadequate designs. ${ }^{17}$ Barriers exist both from patients' and nurses' perspectives, which may hinder meaningful care interventions. ${ }^{518-21}$ This is not surprising, as health promotion researchers have pointed out that health problems relating to lifestyle are morally complex by nature. ${ }^{22}$

In 2011, the Danish regions introduced a new health promotion strategy in psychiatric hospital departments. ${ }^{23}$ The strategy comprised a screening procedure for risk factors (such as diet, smoking, alcohol and physical activity) and consultation interviews with people with mental illness. In most of these departments, mental health nurses are asked to screen for risk factors in their first consultation interview with patients admitted to the hospital. If patients are interested in changing an unhealthy lifestyle, mental health nurses should support this. These screenings and consultation interviews are categories in the departments' registration system where mental health nurses document their work, and are tied to the funding system of the department. As such, every time a mental health nurse documents a screening, it counts as a service for which the department receives funding.

Several studies have explored nurses' perspectives and attitudes on health promotion in mental health care. Some focus on specific topics such as physical activity, ${ }^{24}$ smoking $^{25}$ and obesity, ${ }^{8}{ }^{11}$ while others provide a more general perspective on attitudes, practices and knowledge. ${ }^{26-28}$ The latter studies, in particular, suggest that despite mental health nurses having positive attitudes towards supporting the physical health of patients with mental illness, barriers make it difficult to translate these positive attitudes and intentions into practice. Knowledge is thus needed about how mental health nurses experience working with systematic health promotion initiatives in the hospital setting. In this article, we focus on the procedure of screening for risk factors as an example of a health promotion initiative in mental health care and the most common health promotion strategy in a hospital setting. This study aimed to explore how mental health nurses experience performing the screening of risk factors among patients with mental illnesses as part of their health promotion activities.

\section{METHOD}

\section{Design}

This study employed a qualitative research design using an interactive approach based on focus groups to generate data about mental health nurses' experiences with health promotion activities in their everyday practice..$^{29}$ Although individuals might find it hard to discuss work matters, group discussions encourage participants to articulate their responses ${ }^{30}$ and respond to each other's ideas and opinions. Thus, focus groups rely on social groups' interactions $^{31}$ and make it possible to gain insights into mental health nurses' experiences of the opportunities and challenges associated with working with health promotion in psychiatric institutions.

\section{Participants}

Becoming a mental health nurse in Denmark involves first undertaking general nursing training, then gaining practical experience, and finally undertaking 1-year specialist training in mental health nursing. Danish mental health nurses attending this specialist training in the Central Denmark Region between August 2017 and June 2019 were invited (face-to-face) to participate in a focus group. The participants were selected using purposeful sampling based on a homogeneity strategy ${ }^{32} 33$ in order to gain rich descriptions of the specific setting. The group of participants can be characterised as homogeneous as the mental health nurses are a particular group of interest, because of their interest in specialist training and health promotion, and they were very knowledgeable about and experienced in health promotion in mental health care practice. ${ }^{33} 34$ They were recruited from two classes (from 2017/2018 and 2018/2019) undertaking this 1-year specialist training. Twenty-seven nurses participated in the first class ( 1 male and 26 female) and 32 participated in the second class ( 1 male and 31 female). All of the focus group participants were female, and their work experience ranged from 3 to 10 years (see table 1). The mental health specialist training featured a 2-day module on health promotion and health pedagogy which was taught by the first author. The approach took account of the limited time frame, as the participants were recruited after the module. Both groups were invited by the course manager (independently of the author group) to participate. The first group was invited at the end of their specialist training, after the second day of the health promotion training. The second group was invited after

Table 1 Charateristics of mental health nurses participating in focus group

Employment in clinical department

\begin{tabular}{llllll} 
& $\begin{array}{l}\text { Number of nurses } \\
\text { invited }\end{array}$ & $\begin{array}{l}\text { Number of } \\
\text { participants }\end{array}$ & $\begin{array}{l}\text { Forensic } \\
\text { psychiatry }\end{array}$ & $\begin{array}{l}\text { Out patients } \\
\text { clinic }\end{array}$ & $\begin{array}{l}\text { Community } \\
\text { mental health } \\
\text { care }\end{array}$ \\
\hline Focus group 1 & 26 & 7 & 1 & 5 & 1 \\
Focus group 2 & 23 & 5 & 3 & 1 & 1 \\
\hline
\end{tabular}


Box 1 Example of a mental health nurse's case description

"A general challenge is that many of the hospitalized patients smoke cigarettes. It is my experience that we do not talk to the patients about their smoking habits because we think, and observe, that they already face enough problems regarding their mental disease and therefore lack the energy to either cut back on their cigarette use or stop smoking. Thus, I think it is a challenge to promote health in relation to smoking during hospitalization. I also find it challenging talking to the patients regarding the possible consequences of smoking, and whether they wish to stop smoking and how to support them best. We do not have any information material at the ward regarding smoking cessation supports they can apply for after hospitalization or have us help them start on during their hospitalization."

the first day of their health promotion module and thus at the beginning of their specialist training. There was no assessment or working relation between the first author and the participants.

\section{Data collection}

As a part of the course, the mental health nurses were asked to submit a written assignment consisting of one or two case descriptions of challenges they were confronted with in their daily healthcare practices as health promoters working with mental health patients (an example of which is described in box 1). The case descriptions were used as a point of departure for developing a semi-structured interview guide. ${ }^{35}$ The three authors read the 59 case descriptions including those of nurses who did not participate in the interviews. The prevailing themes informed the semi-structured interview guide (see online supplemental appendix 1). The first focus interview took place in February 2018 and the second took place in August 2018. The interviews lasted about one and a half hours and were conducted by the first and third authors in a classroom. The theme was "working with health promotion in practice with mental health patients" based on the mental health nurses' case descriptions. The interviews began with a brief introduction to the purpose of the study, encouraging the mental health nurses to share their views and experiences, as well as information regarding the timeframe and confidentiality issues. The interviews were audio-recorded and transcribed verbatim by the second author.

\section{Data analysis}

The interactive approach pays attention to the interplay between data and theory. ${ }^{29}$ The analysis takes data as its starting point and we developed a coding structure based on the data and used this together with the interpretations of health promotion and prevention embedded in theories of health. ${ }^{132}{ }^{236}$ We wanted to understand how mental health nurses work with screening as a health promotion activity. Qualitative content analysis was used to analyse the data and the purpose of the content analysis was to describe experiences in a conceptual form. ${ }^{37}$ First, data familiarisation was achieved by repeatedly reading the transcribed texts. The second step involved organising the data with codes. NVivo V.12 software (QSR International, Doncaster, Australia) was used to organise the data and facilitate the analysis. In this early stage of the analysis, we considered all of the data equally before adding codes in order to gain an understanding of the variations within the material. Investigating variations within one's data is described as one of the key steps to achieving data saturation. ${ }^{38}$ At this point, the transcripts showed that the mental health nurses faced dilemmas which they managed using different strategies. Hence, the categories dilemmas and strategies were abstracted and sorted into subcodes. In the third step, codes that fell under the two categories were identified by the three authors. At this stage, analysis went back and forth between categories, codes and subcodes. In the fourth step, all of the authors discussed subcodes and codes before the final version was agreed (see online supplemental appendix 2. The coding system). We applied the COREQ checklist to ensure comprehensive reporting of the study (see online supplemental appendix 3 ). ${ }^{39}$

\section{Ethics}

Participants were informed about the authors' confidentiality agreements, and participant anonymity was assured. Written informed consent was obtained from all of the participants to audio-record the interview. All mental health nurses attending the classes provided written consent allowing us to use their written assignments.

\section{Patient and public involvement}

This research was done without patient involvement. Patients were not invited to comment on the study design and were not consulted to develop patientrelevant outcomes or interpret the results. Patients were not invited to contribute to the writing or editing of this document for readability or accuracy.

\section{RESULTS}

Results are described using the main categories illustrating how working with health promotion in mental healthcare practice took place: (1) dilemmas that emerged and (2) the mental health nurses' strategies used to navigate the system.

\section{Dilemmas}

Our analysis showed that the mental health nurses working with the health promotion initiative in their healthcare practice experienced two different types of dilemmas: health promotion-related dilemmas and system-related dilemmas. In the following sections, we provide an analysis of these dilemmas.

\section{Health promotion-related dilemmas}

\section{Discrepancy between the recommended health promotion and} patients' wishes

A key dilemma related to respecting patients' autonomy at the same time as promoting health. In the mental 
health nurses' experience, addressing an unhealthy lifestyle was often at odds with the interests of the patient or even opposed the patient's autonomy, and this created conflict, as witnessed in the following dialogue excerpt between two mental health nurses:

Nurse 1: But some of my patients say, 'I am so unhappy about my life. I am happy when I sit and watch television, and I don't want to go out for a walk'. So, the talk about a better and longer life for mental health patients at the same time as ensuring patient centeredness is difficult. It's difficult for me to make the point 'It would be good for you if you could just walk to the grocery store', if it's followed by them saying, 'No, I can just get them delivered.' You know?

Nurse 2: Yes, who defines the good life in these situations, right?

(Focus group 2, Nurse 4)

The discrepancy between patients' perceptions of and wishes for a good life and the mental health nurses' aims of promoting health was a recurrent pattern in the interviews, and they often found that their efforts to promote health were rejected by the patients. Even the very mention of topics like smoking, obesity or drug abuse could result in a strong reaction from the patients, jeopardising the mental health nurses' efforts to build a relationship and alliance with the patients. They stressed how a good nurse-patient relationship is the cornerstone of any work they undertook with patients with mental illnesses and how the health promotion initiatives threatened this relationship because the patients perceived them to be dictating how they should live their lives.

\section{Prioritising between health promotion and patient care}

Another dilemma associated with health promotion activities was prioritising health promotion activities at the same time as performing other healthcare tasks. Often, mental health nurses found that health promotion was not the most relevant activity to take into consideration:

I think that we need to weigh up what we do all the time. We know that smoking is unhealthy, but maybe something else is more important for the patient? We constantly need to evaluate what to dig into. We know we have to promote health, but we must at the same time minimise any coercion. (Focus group 2, Nurse 2)

Occasionally, promoting health was felt to be meaningless and even wrong. This was due to the clinical context of the psychiatric hospital department. Patients in these departments were often perceived to be too mentally ill or struggling with such serious psychiatric problems that asking about lifestyle seemed irrelevant and sometimes even unethical. As one mental health nurse put it:

We've got a lot of patients in psychiatry who've smoked like chimneys for years. And that puts us in a dilemma, if we are to live up to the National Health
Board guidelines because that means that we need to focus on ways of making the patients stop smoking. At the same time, when patients are admitted, they are doing very poorly, and it seems unethical to talk to them about smoking. (Focus group 1, Nurse 5)

This was a recurrent finding. Mental health nurses felt ambivalent, frequently finding themselves in situations where health promotion did not make sense. This dilemma was described as trying to help patients achieve better health through health promotion activities, at the same time as this seemed useless-if not directly damaging the patients by making them feel bad about habits they did not wish to change:

We ask: 'Do you feel like stopping smoking?' 'No'. Then we document that the patient is not interested in stopping smoking at this point in time. 'Are you interested in quitting drinking [alcohol]?' 'No', the patient is not interested in quitting drinking. The patient knows that he or she ought to do more physical exercise... So despite the best of intentions, what we end up doing is upsetting people who already feel really bad about themselves. (Focus group 1, Nurse 3)

In addition, many hospital departments instructed mental health nurses to ask patients about risk factors (eg, diet, smoking, alcohol and physical activity) during the first consultation interview, timing that accentuated the feeling that asking such questions was morally inappropriate, given the patient's situation.

\section{System-related dilemmas}

The participants described types of dilemmas that originated from structural factors and working conditions. There was a discrepancy between what one might call the system logic of screening and the mental health nurse logic of health promotion. This is to be understood on several levels. First, the system framework where departments received money for their work with health promotion focused solely on screening for risk factors and a limited range of specific activities. The mental health nurses, however, expressed that this by no means gave a realistic picture of actual health promotion activities. They repeatedly stated that health promotion in psychiatry is a much broader, more long-term process than what is possible to document and thus receive payment for in the departments. However, the mental health nurses experienced that their real health promotion work with patients was not acknowledged by the system, financially or professionally:

I think it's a paradox that we address the importance of talking about risk factors (KRAM [Danish acronym for nutrition, physical activity, alcohol consumption and smoking]), when maybe both for the patients and us it's more meaningful to talk about things that matter to the patient, which s/he finds difficult and hopes to work with. Things like loneliness or social relations. But I cannot document such things in the 
'KRAM screening', because it is not part of that system/document. So I am not measured in terms of actually talking to the patient about the things that are meaningful to him or her-and thus promoting health. (Focus group 1, Nurse 2)

Second, working in hospital departments meant that the timeframe was limited. The mental health nurses identified that they could only initiate a process of change in their patients, but they never had the time to follow up on or maintain the health promotion process, due to patients being discharged from hospital. They depended on other health professionals taking over, without having a clear opportunity to 'hand over' or communicate with the patient's GP, for example:

In my experience, patients don't contact their GP or social psychiatry, because there is no bridging in that transition. We can have a good relationship, but the next time I see the patient, nothing has happened. So we often lose them because we refer them on to others, and we expect that our cognitively challenged patients make that contact themselves. (Focus group 1 , Nurse 2)

Third, the mental health nurses felt in various ways that they could not offer what the patients needed. Some described how they lacked sufficient opportunities for activities, such as physical exercise or tailored smoking cessation programmes. In some cases, the department food was considered an invitation to buy a takeaway.

All in all, these system-related dilemmas caused frustration and sometimes even prevented the mental health nurses from initiating health promotion activities. They expressed the need to go back to working concretely with health promotion in the departments in order to work with patients about healthy lifestyles:

You sometimes get caught in this feeling of 'What's the use?' I sometimes feel like I only have the patients for a few seconds, and I risk saying to them: 'Not only do you have all these mental illnesses, but there are a lot of things that you aren't in control of and are doing wrong-but have a nice time at the outpatient clinic!' Without any bridging where we meet and talk together. So sometimes you just let things lie because you only risk opening up Pandora's box and not being able to close it again. (Focus group 1, Nurse 4)

Despite these dilemmas, challenges and sometimes perceptions of meaninglessness, the mental health nurses found that working with health promotion in mental health care was important, and that if it were combined with more flexibility and closer cooperation across the healthcare system, it would be meaningful.

\section{Strategies for navigating the system}

The mental health nurses developed and executed different strategies for clinical practice and other healthcare tasks. The nurses organised their work and their communication to ensure that their patients did not have any negative experiences due to the screening. We identified two strategies used to navigate the system: developing interview techniques and finding solutions.

\section{Developing interview techniques}

The mental health nurses developed different interview techniques that they used when talking to the patients to make sense of screening for risk factors-both for themselves and their patients. This was because they experienced addressing risk factors as potentially confrontational or irrelevant. They therefore came up with alternative ways of asking the questions that were dictated by the screening. One of the mental health nurses explained how she tried to make screening as relevant as possible for the patients, at the same time as avoiding being judgemental:

"[...] I try [to ask, ed.] my patients: what does it mean to them when one talks about KRAM? What is a good life? You know, making it about how they go about their day, if they drink 5 or 6 beers or they smoke $\mathrm{x}$ number of cigarettes. Because that's quality and health for them, and then I don't start nagging." (Focus group 1, Nurse 3)

Others expressed how they distanced themselves from the screening by letting the patient know that they did not approve of it, for example, by referring to screening for risk factors as a 'must-do' task:

I usually tell the patients I have known for a long time: "this is a 'must-do' task, so should we not just get it done?" (Focus group 1, Nurse 5)

Especially questions about substance abuse created challenges during screening.

These strategies were used to navigate this particular issue, and some mental health nurses even 'intentionally forgot to ask' questions so as to prevent patients refusing to talk with them.

\section{Finding solutions}

Another strategy involved developing concrete activities that deviated somehow from the guidelines and activities normally offered. Some mental health nurses labelled these 'under the counter' solutions or described them as 'bending the rules'. These referred to things such as organising training possibilities and outdoor activities for patients beyond what was actually allowed in the system, or finding ways of keeping in contact with patients after discharge, despite the hospital not being paid for this, in order not to 'lose the patients' but instead facilitate their gradual transition to everyday life.

Part of the mental health nurses' risk factor screening involved registering the information obtained in the data system. However, this approach did not align with their professional judgements and their views on focusing on individual patients' special needs. Thus, the mental health nurses felt forced to bend the rules in order to 
maintain a relationship with their patients and provide good care.

Another kind of deviation happened when the mental health nurses promoted a non-healthy lifestyle to the patients. For example, the mental health nurses would occasionally provide the patients with cigarettes to help them to calm down or if they thought it would somehow improve the patient's mental health.

It is primarily patients with severe depression that are hospitalized at my ward, so sometimes you ask, just to get the patient out of bed: 'Are you not going out to smoke?' Simply to get the patient up. And I actually think that is okay even though I know that it is unhealthy to smoke. It's not what the patient is there for, smoking, it's because of their mental illness. Acute psychiatry is our focus, not smoking. (Focus group 1, Nurse 1)

The nurses did not think their primary role was to make their patients stop smoking but to take care of their mental illness. Because of this, they acted against the system's aims to make mental health patients adopt a healthier lifestyle. Several mental health nurses called this necessary 'civil disobedience'.

Yes, you learn to bend the rules. You do what they say and still avoid the patient getting into trouble. (Focus group 2, Nurse 1)

One mental health nurse told about her success in navigating the system and using opportunities for government funding. She applied for and received extra funding for a project to promote health among patients who overused drugs. Initially, it was a temporary project financed by the government that provided her and her colleagues with resources to follow up on discharged patients whom the mental health nurses considered needed support with settling into everyday life outside the hospital. In the project, a small group of patients met once a week and received assistance and help from the nurses. After the project period, local management made the project a permanent offer. The mental health nurse could thus offer patients the type of assistance after discharge that everyone agreed to be most beneficial, but that was not more generally available:

Nurse 3: I was lucky that when I told the management about my interest in continuing to work more long term with the patients, they let me. It requires management support. So, after the patients are discharged, we meet with a group of 7-12 patients one hour every week. That's all it takes.

Nurse 4: That makes so much sense. Then it [health promotion, ed.] is meaningful, instead of just pointing out 'you ought to quit smoking and drinking.' (Focus group 2)

This was an example of how health promotion activities were meaningful. However, it took extra effort from the individual nurse, management support and luck to make it happen.

The aforementioned strategies and ways of navigating the system were employed to overcome dilemmas that emerged because of discrepancies between health promotion aims and healthcare practices. The mental health nurses sought to create, maintain and confirm a relationship with their patients through using these strategies.

\section{DISCUSSION}

This study showed that while mental health nurses found it meaningful to focus on health promotion activities in mental health care, these activities created dilemmas in their work. One dilemma related to health promotion, which involved discrepancies between patients' autonomy and wishes, on the one hand, and the health promotion activities offered, on the other hand. Another, system-related dilemma stemmed from working with the screening and documentation programme for risk factors. The nurses developed different strategies to navigate these dilemmas, developing interview techniques for screening questions and finding new solutions to make health promotion fit usual practices.

Our study focused primarily on the implementation of a particular health promotion initiative (screening for risk factors) and not health promotion in healthcare practice as a whole. A study with a broader scope (for example, using observations of the mental health nurses' practices) could have captured a more nuanced picture of how health promotion is embedded in daily practices, and also provided more detailed insights into how health promotion converges with healthcare practice. An intervention study on smoking cessation from the UK was conducted in primary care and showed that long-term smoking cessation (after 1 year) was difficult to achieve. ${ }^{40}$ Still, our scope enabled us to analyse how screening for risk factors as the chosen strategy of health promotion affects healthcare practice and creates discrepancies in terms of aims.

Our study relates specifically to the Danish context and the way health promotion in psychiatric hospital practice in Denmark is performed mainly in terms of screening for risk factors. The literature reports on similar international tendencies where health promotion focuses on physical fitness and risk factors and not broader understanding, ${ }^{22}$ suggesting that our findings could be transferable more generally.

Our material consists of two focus group transcripts, and thus a low number of participating nurses. This is a methodological limitation as it prevented us from achieving full data saturation. We found repeated themes and variations, but we cannot rule out the possibility that new themes would have appeared had we conducted more focus group interviews. We did not include member checking to secure validity, which might also be seen as a limitation. Some researchers have criticised the value of member checking, ${ }^{35}$ but member checking 
is considered important, for example, in participatory action research. In our design, member checking using transcripts from focus groups was not possible as the utterances depended on each other and created collective negotiated meanings, and we did not explicitly ask the participants for permission to share the transcripts between them. To triangulate and validate the focus group interviews, we had written cases from the participants and the other course participants. Moreover, in the Methods section, we described the coding and analysis in detail to secure transparency within the research process. The use of mental health nurses' written cases allowed us to check consistency in the content of the focus group interviews, and thus served to validate these. In addition, all three authors coded the material, thus employing researcher triangulation to validate the findings. These initiatives increased the credibility of our findings.

Using purposeful sampling meant that the included nurses had positive attitudes towards health promotion and prevention, were experienced in mental health, and were interested in obtaining better knowledge and skills to provide good healthcare for their patients, because they chose to participate in the course. As these nurses experienced dilemmas, we anticipate that other mental nurses are likely to face similar dilemmas.

The mental health nurses expressed a tension between how they would like to work with health promotion through broader intervention over time, and what type of health promotion work the system allowed them to do. Screening for risk factors seemed more or less meaningless in some situations. At the same time, the mental health nurses wished to work with health promotion, especially in situation where talking about the risk factor felt more appropriate to integrated in the conversation with the patient. This ambivalence is also known from other studies. ${ }^{824}$

This study adds to the findings of the previous study by Nash and Romanos ${ }^{25}$ and Özaslan et a $t^{42}$ where cigarettes were used as an 'intervention' aimed at promoting socially acceptable behaviour. In the present study, the mental health nurses explained that it was not a case of being unconcerned with the mental health patients' physical health but a matter of prioritisation. They agreed that it was more important for the patients to achieve better mental health than stop smoking.

The study by Verhaeghe et al indicated that mental health nurses considered themselves the best suited to support mental health patients in changing their unhealthy lifestyles. ${ }^{11}$ However, they reported that lack of time was an important barrier to integrating health promotion activities into the daily care of patients. In keeping with this, the present study found that barriers to supporting patients with improving their physical health were often system related. For example, mental health nurses found that their health promotion work with patients was not acknowledged by the system financially or professionally, and that working in hospital departments meant that the timeframe for health promotion was limited. Implementation success depends on both individual and organisational factors. ${ }^{43}$ The professionals' attitudes towards change are influenced by their working environment, work conditions and organisational characteristics. ${ }^{44}$ A recent study suggests that new interventions must connect with existing practices, and that local management support is important when implementing health promotion initiatives in community mental health services. ${ }^{20}$

In the study by Mwebe, ${ }^{5}$ mental health nurses viewed the monitoring and screening of the physical health needs of service users as vital, as they acknowledged that both physical and mental health needs were equally important and should receive the same attention from health professionals. Our study provides further nuancing to this picture. The mental health nurses described a dilemma, as they often experienced that health promotion-defined as screening-was not the most relevant activity, or was even meaningless or wrong, for example, when activities to improve a healthy lifestyle opposed what patients found to be relevant in their lives.

Studies have identified that the attitudes and skills of mental health nurses play a role in promoting health for patients with mental illness. ${ }^{26}{ }^{45}$ Sheals et al found that mental health professionals may have attitudes and misconceptions that undermine the delivery of smoking cessation interventions. ${ }^{46}$ Other studies show that although mental health nurses have positive attitudes to providing physical health care to patients with severe mental illness, barriers exist that prohibit translating those attitudes and intentions to actual clinical practice, for example, lack of knowledge and skills to address physical health care. ${ }^{26} 47$ Targeting the educational needs of nurses and using practical guidelines on screening and intervening in mental health services have been suggested. ${ }^{47}$ Our study adds to this picture by showing that even though mental health nurses have knowledge and positive attitudes, dilemmas still occur in daily practice when screening for risk factors.

We add to existing studies by showing how mental health nurses developed strategies to overcome the dilemmas that emerge when implementing health promotion in mental health care, such as opposing the understanding of health promotion in terms of risk factors. The nurses acknowledge the need for a holistic, person-centred and evidence-based approach to both mental health care and health promotion activities. In our study, the limited understanding of health promotion was embedded in the system, as screening was understood as a reductive approach to individuals' mental health care. The nurses' ability to navigate the system thus differs from a study showing that nurses' perceptions of health promotion are limited and narrow. ${ }^{48}$ Future research should address the relation between mental health nurses' knowledge and context, and not merely their knowledge. This would lead to new insights into the complexity in this field as opposed to only partial aspects.

Health promotion strategies are based on a broad understanding of health and aim to promote the health 
and well-being of the population, including both individual and structural elements. Thus, successful lifestyle interventions for people with severe mental illness have multiple components: they are tailored to the individual, long-term based and address both the group and the system. ${ }^{1349}{ }^{50}$ However, the diagnostics and treatment of psychiatric disorders in the Danish healthcare system are mainly based on medical and psychological knowledge of disease, psycho-education and medication. The dilemmas experienced by the mental health nurses may be related to the concept of health being both disease oriented and autonomy oriented, which finds support in the literature. ${ }^{51}$ The first one is grounded in biomedical understandings of health, diagnosis and objective measures of health outcomes, while the second refers to the individual's ability to be in control and have power over their own life situation. ${ }^{36}$ Screening of risk factors can be considered a disease-oriented preventive initiative stemming from the biomedical approach that might not address the needs of the individual person at a specific point in time and enable the person to take control and improve their health. Studies suggest that screening of risk factors should be coupled with other health promotion initiatives. In the analysis, we show how nurses navigate the clash between a health promotion and a prevention approach.

In conclusion, our findings show that new health promotion activities in mental health care need to be adapted to nurses' existing mental healthcare practices; however, this may require some adaptation of existing nursing practices. Health promotion activities must have a broader scope than risk factors and address long-term physical and mental health care in order to be meaningful.

Correction notice This article has been corrected since it first published. The provenance and peer review statement has been included.

Acknowledgements The authors wish to thank the students in the postgraduate mental health nursing education programme who volunteered to share their written reflections and participate in the interviews. In addition, the authors would like to thank Lotte Herskind for her administrative support for the study.

Contributors We hereby confirm that all authors meet the authorship criteria in accordance with the International Committee of Medical Journal Editorial. All of the authors have contributed sufficiently to this work to be listed as authors, and have made substantial contributions to conception and design, or acquisition of data, or analysis and interpretation of data; have been involved in drafting the manuscript and revising it critically for important intellectual content; and have given final approval of the version to be published. Each author has participated sufficiently in the work to take public responsibility for appropriate portions of the content and agreed to be accountable for all aspects of the work. Conception and design: JEM, AM, LL. Acquisition of data: JEM, LL. Analysis and interpretation of data: JEM, AM, LL. Writing original manuscript: JEM, LL. Writing —review and editing: JEM, AM, LL.

Funding The authors have not declared a specific grant for this research from any funding agency in the public, commercial or not-for-profit sectors.

Competing interests None declared.

Patient consent for publication Not required.

Ethics approval The study was approved by the Danish Data Protection Agency (Journal no. 2016-051-000001, №. 1252). The study did not require approval from the Central Denmark Region Committee on Health Research Ethics, according to the Consolidation Act on Research Ethics Review of Health Research Projects.

Provenance and peer review Not commissioned; externally peer reviewed.
Data availability statement No data are available.

Supplemental material This content has been supplied by the author(s). It has not been vetted by BMJ Publishing Group Limited (BMJ) and may not have been peer-reviewed. Any opinions or recommendations discussed are solely those of the author(s) and are not endorsed by BMJ. BMJ disclaims all liability and responsibility arising from any reliance placed on the content. Where the content includes any translated material, BMJ does not warrant the accuracy and reliability of the translations (including but not limited to local regulations, clinical guidelines, terminology, drug names and drug dosages), and is not responsible for any error and/or omissions arising from translation and adaptation or otherwise.

Open access This is an open access article distributed in accordance with the Creative Commons Attribution Non Commercial (CC BY-NC 4.0) license, which permits others to distribute, remix, adapt, build upon this work non-commercially, and license their derivative works on different terms, provided the original work is properly cited, appropriate credit is given, any changes made indicated, and the use is non-commercial. See: http://creativecommons.org/licenses/by-nc/4.0/.

ORCID iD

Jane Ege Møller http://orcid.org/0000-0003-2661-0256

\section{REFERENCES}

1 Danish Health Authority. Styrket indsats for mennesker med psykiske lidelser - Fagligt oplæg til en samlet plan for psykiatriens udvikling [A strengthened effort for people with mental disorders. A professional proposal for a comprehensive plan for the development of psychiatry], 2018. Available: https://www.sst.dk/da/nyheder/2018/ / media/34222C94E2C24ABEBBE6C1F2DF1F56F0.ashx [Accessed 13 Dec 2018].

2 McCloughen A, Foster K, Marabong N, et al. Physical health risk behaviours in young people with mental illness. Issues Ment Health Nurs 2015;36:781-90.

3 Scheewe TW, Jörg F, Takken T, et al. Low physical activity and cardiorespiratory fitness in people with schizophrenia: a comparison with matched healthy controls and associations with mental and physical health. Front Psychiatry 2019;10:87.

4 Laursen TM, Munk-Olsen T, Gasse C. Chronic somatic comorbidity and excess mortality due to natural causes in persons with schizophrenia or bipolar affective disorder. PLoS One 2011;6:e24597-7.

5 Mwebe $\mathrm{H}$. Physical health monitoring in mental health settings: a study exploring mental health nurses' views of their role. J Clin Nurs 2017;26:3067-78.

6 Wahlbeck K, Westman J, Nordentoft M, et al. Outcomes of Nordic mental health systems: life expectancy of patients with mental disorders. Br J Psychiatry 2011;199:453-8.

7 Annamalai A, Singh N, O'Malley SS. Smoking use and cessation among people with serious mental illness. Yale J Biol Med 2015;88:271.

8 Verhaeghe N, De Maeseneer J, Maes L, et al. Perceptions of mental health nurses and patients about health promotion in mental health care: a literature review. J Psychiatr Ment Health Nurs 2011;18:487-92.

9 Thornicroft G. Premature death among people with mental illness. BMJ 2013;346:f2969-2.

10 Colton CW, Manderscheid RW. Congruencies in increased mortality rates, years of potential life lost, and causes of death among public mental health clients in eight states. Prev Chronic Dis 2006;3:1-14.

11 Verhaeghe N, De Maeseneer J, Maes L, et al. Health promotion in mental health care: perceptions from patients and mental health nurses. J Clin Nurs 2013;22:1569-78.

12 Wand T, Murray L. Let's get physical. Int J Ment Health Nurs 2008;17:363-9.

13 WHO. Ottawa Charter for Health Promotion. First International Conference on health promotion. Available: http://www.who.int/ healthpromotion/conferences/previous/ottawa/en/ [Accessed 23 Oct 2018].

14 WHO. New players for a new era - leading health promotion into the 21st century.1997 fourth International Conference on health promotion. Available: http://www.who.int/healthpromotion/ conferences/previous/jakarta/en/ [Accessed 23 Oct 2018].

15 WHO. Health 2020: a European policy framework supporting action across government and society for health and well-being, 2013. Available: http://www.euro.who.int/_data/assets/pdf_file/0006/ 199536/Health2020-Short.pdf?ua $=1$ [Accessed 4 Feb 2019].

16 WHO. Milestones in health promotion: statements from global conference, 2009. Available: http://www.who.int/healthpromotion/ 
Milestones_Health_Promotion_05022010.pdf [Accessed 23 Oct 2018].

17 Gossage-Worrall R, Hind D, Barnard-Kelly KD, et al. Structured lifestyle education for people with schizophrenia (stepwise): mixed methods process evaluation of a group-based lifestyle education programme to support weight loss in people with schizophrenia. BMC Psychiatry 2019;19:358.

18 Jerdén L, Hillervik C, Hansson A-C, et al. Experiences of Swedish community health nurses working with health promotion and a patient-held health record. Scand J Caring Sci 2006;20:448-54.

19 Jormfeldt H, Svedberg P, Arvidsson B. Nurses' conceptions of how health processes are promoted in mental health nursing. $J$ Psychiatr Ment Health Nurs 2003;10:608-15.

20 Kleemann E, Bracht CG, Stanton R, et al. Exercise prescription for people with mental illness: an evaluation of mental health professionals' knowledge, beliefs, barriers, and behaviors. Braz $J$ Psychiatry 2020;42:271-7.

21 Burau V, Carstensen K, Fredens M, et al. Exploring drivers and challenges in implementation of health promotion in community mental health services: a qualitative multi-site case study using normalization process theory. BMC Health Serv Res 2018;18:36.

22 Buchanan DR. An ethic for health promotion - rethinking the sources of human well-being. New York: Oxford University Press, 2000.

23 Danish Regions. Kvalitet i psykiatrien: Ny dagsorden for diagnostik og behandling. [Quality in psychiatry: a new agenda to diagnostics and treatment], 2011. Available: https://www.regioner.dk/media/ 1235/kvalitet-i-psykiatrien.pdf [Accessed 23 Oct 2018].

24 Faulkner G, Biddle S. Mental health nursing and the promotion of physical activity. J Psychiatr Ment Health Nurs 2002;9:659-65.

25 Nash MJ, Romanos MT. An exploration of mental health nursing students' experiences and attitudes towards using cigarettes to change client's behaviour. J Psychiatr Ment Health Nurs 2010;17:683-91.

26 Bressington D, Badnapurkar A, Inoue S, et al. Physical health care for people with severe mental illness: the attitudes, practices, and training needs of nurses in three Asian countries. Int J Environ Res Public Health 2018;15:343.

27 Gray R, Brown E. What does mental health nursing contribute to improving the physical health of service users with severe mental illness? A thematic analysis. Int J Ment Health Nurs 2017;26:32-40.

28 Lundström S, Jormfeldt $\mathrm{H}$, Hedman Ahlström B, et al. Mental health nurses' experience of physical health care and health promotion initiatives for people with severe mental illness. Int $J$ Ment Health Nurs 2020;29:244-53.

29 Maxwell JA. Qualitative research design: an interactive approach Thousand Oaks, CA: SAGE, 2013.

30 Barbour RS. Focus groups. In: Bourgeault IL, Dingwall R, De Vries $\mathrm{RG}$, eds. The SAGE handbook of qualitative methods in health research. London: SAGE, 2013.

31 Morgan DL. Focus groups as qualitative research. 2nd ed. Thousand Oaks, CA: SAGE, 2000.

32 Palinkas LA, Horwitz SM, Green CA, et al. Purposeful sampling for qualitative data collection and analysis in mixed method implementation research. Adm Policy Ment Health 2015;42:533-44.

33 Patton MQ. Qualitative research and evaluation methods. 3rd ed. Thousand Oaks, CA: Sage Publications, 2002: 37.
34 Cresswell JW, Plano Clark VL. Designing and conducting mixed method research. 2nd ed. Thousand Oaks, CA: Sage, 2011.

35 Sandelowski M. Member Check. In: Given LM, ed. The SAGE encyclopedia of qualitative research methods. Thousand Oaks: SAGE Publications, 2008.

36 Juul Jensen U. Sundhedsbegreber, selvansvarlighed og stat. [Concepts of health, self-responsibility and the state]. KvaN 2008;2008:7-26.

37 Elo S, Kyngäs $\mathrm{H}$. The qualitative content analysis process. $J$ Adv Nurs 2008;62:107-15.

38 Saumure K, Given LM. Data saturation. In: Given LM, ed. The SAGE encyclopedia of qualitative research methods. Thousand Oaks: SAGE Publications, 2008

39 Tong A, Sainsbury P, Craig J. Consolidated criteria for reporting qualitative research (COREQ): a 32-item checklist for interviews and focus groups. Int J Qual Health Care 2007;19:349-57.

40 Gilbody S, Peckham E, Bailey D, et al. Smoking cessation for people with severe mental illness (SCIMITAR+): a pragmatic randomised controlled trial. Lancet Psychiatry 2019;6:379-90.

41 Kvale S. InterViews: an introduction to qualitative research interviewing. Thousand Oaks, CA: Sage, 1996.

42 Özaslan Z, Bilgin H, Uysal Yalçın S, et al. Initial psychometric evaluation of the physical health attitude scale and a survey of mental health nurses. J Psychiatr Ment Health Nurs 2020;27:62-76.

43 Rye M, Friborg O, Skre I. Attitudes of mental health providers towards adoption of evidence-based interventions: relationship to workplace, staff roles and social and psychological factors at work. BMC Health Serv Res 2019;19:110.

44 Wynaden D, Heslop B, Heslop K, et al. The chasm of care: where does the mental health nursing responsibility lie for the physical health care of people with severe mental illness? Int J Ment Health Nurs 2016;25:516-25.

45 Happell B, Scott D, Platania-Phung C. Perceptions of barriers to physical health care for people with serious mental illness: a review of the international literature. Issues Ment Health Nurs 2012;33:752-61.

46 Sheals K, Tombor I, McNeill A, et al. A mixed-method systematic review and meta-analysis of mental health professionals' attitudes toward smoking and smoking cessation among people with mental illnesses. Addiction 2016;111:1536-53.

47 Hennessy S, Cocoman AM. What is the impact of targeted health education for mental health nurses in the provision of physical health care? An integrated literature review. Issues Ment Health Nurs 2018;39:700-6.

48 Casey D. Nurses' perceptions, understanding and experiences of health promotion. J Clin Nurs 2007;16:1039-49.

49 WHO. Health in all policies. Eighth global conference on health promotion, 2013. Available: http://www.who.int/healthpromotion/ conferences/8gchp/en/ [Accessed 23 Oct 2018].

50 Daumit GL, Dalcin AT, Dickerson FB, et al. Effect of a comprehensive cardiovascular risk reduction intervention in persons with serious mental illness: a randomized clinical trial. JAMA Netw Open 2020;3:e207247.

51 Doyle L, Ellilä $\mathrm{H}$, Jormfeldt $\mathrm{H}$, et al. Preparing master-level mental health nurses to work within a wellness paradigm: findings from the eMenthe project. Int J Ment Health Nurs 2018;27:823-32. 